\title{
Preliminary report on regional resistivity variation inferred from the Network MT investigation in the Shikoku district, southwestern Japan
}

\author{
Satoru Yamaguchi ${ }^{1}$, Yoshiaki Kobayashi ${ }^{1}$, Naoto Oshiman ${ }^{2}$, Kengo Tanimoto ${ }^{2}$, Hideki Murakami ${ }^{3}$, \\ Ichiro Shiozaki ${ }^{4}$, Makoto Uyeshima ${ }^{5}$, Hisashi Utada ${ }^{5}$, and Norihiko Sumitomo ${ }^{2}$ \\ ${ }^{1}$ Department of Earth and Planetary Sciences, Faculty of Science, Kobe University, Nada, Kobe 657-8501, Japan \\ ${ }^{2}$ Disaster Prevention Research Institute, Kyoto University, Uji, Kyoto 611-0011, Japan \\ ${ }^{3}$ Department of Geology, Faculty of Science, Kochi University, Kochi 780-8520, Japan \\ ${ }^{4}$ Department of Civil Engineering, Faculty of Engineering, Tottori University, Tottori 680-0945, Japan \\ ${ }^{5}$ Earthquake Research Institute, University of Tokyo, Tokyo 113-0032, Japan
}

(Received November 5, 1996; Revised September 28, 1998; Accepted January 27, 1999)

\begin{abstract}
The Network MT method was used in the eastern part of the Shikoku district, southwestern Japan, and a total of thirty-nine MT impedances (64 to $2560 \mathrm{sec}$ ) were obtained. These MT impedances had their values averaged over a triangular element, whose sides were a few kilometers long with geomagnetic observatory data from the Kakioka Geomagnetic Observatory. Well-determined MT impedances varied from north to south with the greatest differences being at the Median Tectonic Line, which is consistent with the surface geology in the area. In addition, very large or very small values of apparent resistivity were obtained in some triangular elements. These triangles were located on a cape or near an estuary, with effects of three-dimensionality clearly apparent. Stable MT impedances were not obtained for three groups of triangular elements: (1) those where one or two sides of the triangular element cross the coast; (2) those where the electric field was contaminated by severe artificial noise, these were mainly in the northwestern part of the survey area; (3) those where the triangles had an extremely acute- or obtuse-angle.

A resistivity cross section was derived from the TM-mode data for a profile crossing the eastern part of the area. The shallower layer, which approximately corresponds to the crust, was divided into three blocks. Two resistive boundaries coincide with the geological tectonic lines and the strong horizontal contrast found at the Median Tectonic Line. The northernmost block is the most resistive, and the block to the south is the most conductive. Beneath these blocks, the subducting Philippine Sea plate was represented by a thick and highly resistive north-dipping layer. A highly conductive thin layer was found above the resistive layer on the southern side of the Median Tectonic Line. This layer is only found beneath the southern side of the Median Tectonic Line and is probably caused by pore water and/or sediment at the upper plane of the subducting Philippine Sea plate. Another conductive layer was found under the highly resistive north-dipping layer.

The resistivity structure from the lower crust to the upper mantle is firstly obtained using the Network-MT method. However, further developments are needed in methods of data analysis, which are robust to artificial electric noise, in order to clarify the spatial distribution of MT impedances in the complete study area.
\end{abstract}

\section{Introduction}

Electrical conductivity structure of the crust and the upper mantle beneath the Japanese Islands has been clarified in recent years. Sugimura (1978) showed that the Japanese Islands consist of two trench-arc systems: a Northeastern Arc and a Southwestern Arc (Fig. 1). The Northeastern Arc has more typical island arc activities. The arc is situated on the boundaries of the Eurasian plate, the North American plate, the Pacific plate, and the Philippine Sea plate. The Southwestern Arc marks the boundary between the Eurasian plate and the Philippine Sea plate. Sugimura (1978) pointed out that the Southwestern Arc cannot be regarded as a typical island arc. For example, the Nankai trough off the Southwestern Arc is not deep enough to be regarded as a trench; volcanic activity is less active; and there are no deep earthquakes.

Copy right(c) The Society of Geomagnetism and Earth, Planetary and Space Sciences (SGEPSS); The Seismological Society of Japan; The Volcanological Society of Japan; The Geodetic Society of Japan; The Japanese Society for Planetary Sciences.
Along the Northeastern Arc, many deep electrical surveys have been carried out and various authors have proposed resistivity models (e.g., Ogawa et al., 1986; Ogawa, 1987; Utada et al., 1996). Utada et al. (1996) showed the structure of electrical resistivity beneath the Japanese Islands and the surrounding oceans across the northeastern and central parts of Japan. The structure was summarized as follows: a part of the lower crust beneath the Japanese Islands is conductive by more than one order of magnitude compared to the other part of the crust; a highly conductive layer is identified at approximately $150 \mathrm{~km}$ and $30 \mathrm{~km}$ beneath the Pacific Plate and the Philippine Sea Plate; a thin (about $10 \mathrm{~km}$ or less) conductive layer exists on the top of the subducting plate and can be traced deep beneath the Japan Islands.

The resistivity structure has not been as well established in the Southwestern Arc, especially in the Chugoku and Shikoku district, even though these districts are the central region of the Southwestern Arc. Only two attempts have been made so far at constructing the regional conductivity model crossing these districts. Shiozaki (1993) first investi- 


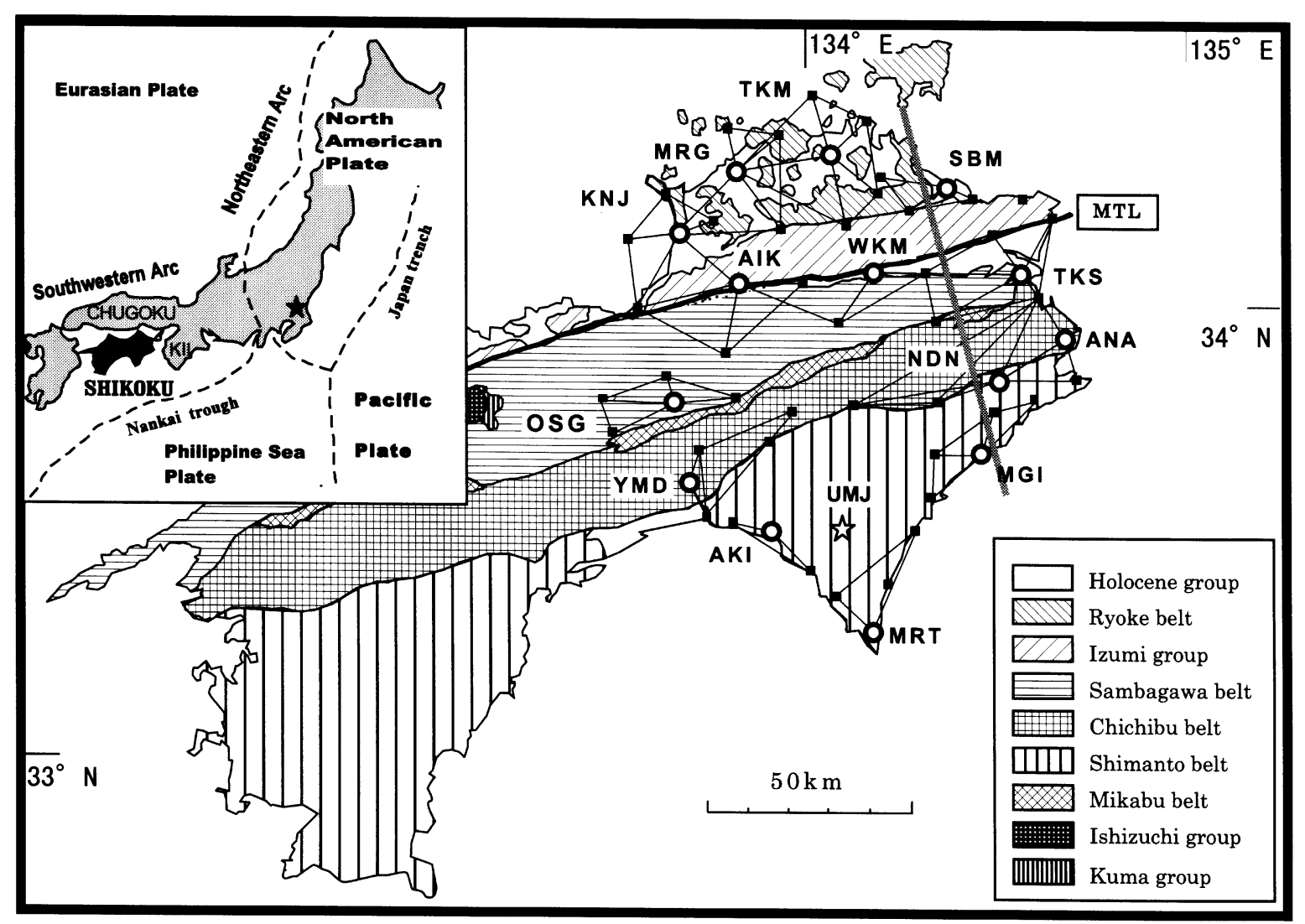

Fig. 1. The spatial distribution of the observation points comprising the Network-MT, in the eastern part of the Shikoku district, southwestern Japan, and geology of the area (after Suyari et al., 1991). The gray line indicates the location of the cross section for the two-dimensional model. The open circles, with abbreviated location names, represent the central stations; the closed squares represent the telephone branch stations. The position of the closed star in the inset indicates the location of the Kakioka Geomagnetic Observatory (KAK). The position of the open star indicates the location of the temporary magnetic observation site (UMJ), which operated from the November to December 1994.

gated the resistivity structure along the N-S line crossing the central part of the Shikoku district, and Fuji-ta et al. (1997) investigated the crustal structure beneath the Kii peninsula, which is located to the east of the Shikoku island, using the MT method.

The Shikoku district of Southwest Japan is characterized by a distinct zonal arrangement of geological terranes (Fig. 1). These are divided into the Inner Zone (Japan Sea side) and the Outer Zone (Pacific side) by a major fault referred as the Median Tectonic Line (Hada et al., 1982). The Inner Zone of the Shikoku district is classified into the Ryoke metamorphic belt and the Izumi Group, and the Outer Zone is classified into the Sambagawa metamorphic belt, the Chichibu belt, and the Shimanto belt, from north to south. These three belts are known to have grown from accretion processes (Taira et al., 1989).

In this paper, we present the spatial distribution of the MT impedances for the eastern part of the Shikoku district, southwestern Japan. Network MT data were obtained using the procedure developed by Uyeshima (1990), and good results have been obtained previously for Hokkaido (Uyeshima, 1990) and for the Tohoku district (Uyeshima, personal communication) using this procedure. The MT impedances used here were averaged over triangular elements with sides of a few kilometers. Next, we also pro- pose a model to explain the profile, $\mathrm{N} 15^{\circ} \mathrm{W}-\mathrm{S} 15^{\circ} \mathrm{E}$, which crosses the eastern part of the study area.

\section{The Network-MT Observation and Analysis}

In the Network MT method (Uyeshima, 1990), telluric fields are measured by means of telephone cables of NTT (Nippon Telegraph and Telephone Corporation) and electric earths of NTT telephone stations. By this means it is possible to obtain differences of the electric potential between very long span electrodes, with separation ranges from a few kilometers to a few tens of kilometers. The electric earths of the telephone stations use copper poles. Figure 1 shows the distribution of branch stations and the central stations of the NTT used. We measured the difference of electric potential between the branch and the central stations.

The merits of Network MT method are summarized as follows (Uyeshima, 1990). First of all, a high signal to noise $(\mathrm{S} / \mathrm{N})$ ratio is achieved as amplitude of the electric field, induced by the geomagnetic field variation in the Earth, depends on dipole length, while electric noise, such as circuit noise, drifts caused by the variation of chemical condition around electrodes, and artificial noise produced by human electrical activity, is virtually independent of electrode spacing. Second, the effect of the static shift can be removed or reduced; we can obtain impedance values which average 
Table 1. A summary of the observations and analysis at each net.

\begin{tabular}{cccccc}
\hline $\begin{array}{c}\text { Central } \\
\text { station }\end{array}$ & $\begin{array}{c}\text { Number of } \\
\text { branches }\end{array}$ & $\begin{array}{c}\text { Observation } \\
\text { period }\end{array}$ & $\begin{array}{c}\text { Length of } \\
\text { data analyzed }\end{array}$ & $\begin{array}{c}\text { Robust } \\
\text { processing }\end{array}$ & $\begin{array}{c}\text { Night time } \\
\text { or all day }\end{array}$ \\
\hline OSG & 4 & 1994 Nov.-Dec. & 1 month & yes & all \\
YMD & 4 & 1994 Nov.-Dec. & 1 month & no & all \\
AKI & 2 & 1994 Nov.-Dec. & 1 month & no & all \\
MRT & 3 & 1994 Nov.-Dec. & 1 month & no & all \\
MGI & 4 & 1994 Nov.-Dec. & 1 month & no & all \\
TKS & 6 & 1995 Feb.-Jun. & 43 days & no & all \\
WKM & 3 & 1995 Feb.-Jun. & 43 days & no & all \\
SBM & 3 & 1995 Feb.-Jun. & 5 months & yes & all \\
TKM & 5 & 1995 Jul.-Nov. & 2 months & yes & all \\
MRG & 4 & 1995 Jul.-Nov. & 2 months & yes & all \\
ANA & 3 & 1995 Jul.-Nov. & 10 days & no & all \\
NDN & 2 & 1995 Jul.-Nov. & 10 days & no & all \\
AIK & 3 & 1995 Jul.-Nov. & 2 months & yes & night \\
KNJ & 4 & 1995 Jul.-Nov. & 2 months & yes & night \\
\hline
\end{tabular}

out the effects of small-scale inhomogeneity of near-surface resistivity, by the use of long dipoles. Third, variation of the impedances of the target area can be estimated effectively, because telephone lines are well distributed in Japan. Fourth, the telephone lines are well protected from animals or leakage, and the earth connections are well grounded, so contact resistance is kept to less than $10 \Omega$.

Computation of an MT impedance value requires both electric and magnetic data. The time series for the electric data were obtained by making five measurements every second. These measurements were made exactly on the second, at $200 \mathrm{msec}$ and $100 \mathrm{msec}$ before the second, at 200 msec and $100 \mathrm{msec}$ after the second. The five measurements were then averaged, to give a reading for that second. Then, ten such readings, for ten consecutive seconds, were averaged, to give a single value. Such single values, at $10 \mathrm{sec}$ intervals, then formed the time series for the electric field. A major purpose of the averaging procedure was to reduce the aliasing effect which may arise in digitized data.

For the magnetic data, records of two horizontal components of the geomagnetic fluctuating field were taken from the Kakioka Geomagnetic Observatory of the Japan Meteorological Agency (KAK in Fig. 1). The validity of using the Kakioka geomagnetic records as a reference will be discussed later. The magnetic data were at $1 \mathrm{sec}$ intervals, as supplied by the observatory. These data were averaged, ten at a time, to give time series at $10 \mathrm{sec}$ intervals, which then matched the electric field data.

The time series were then further filtered, taking one day at a time, by means of a band-pass digital recursive filter (Saito, 1978), with a band pass from $30 \mathrm{sec}$ to $3000 \mathrm{sec}$. The data still at $10 \mathrm{sec}$ intervals were next divided into subsets of 512 data points or 64 data points. These sets were transformed to the frequency domain by means of a Fast Fourier Transformation (FFT) routine after using a cosine taper over 10\% of each end of datasets. Response functions were thus obtained, in the frequency domain, between the variation for the electric potential difference observed at each dipole, and the two components of the horizontal magnetic field. Response functions for period greater than $640 \mathrm{sec}$ were determined from the 512 data point subsets (Bendat and Piersol, 1971). The total data lengths varied from site to site, in a range of ten days to five months (Table 1). A robust method for data processing, developed by Uyeshima (1990) was used for noisy data, in order to obtain well-estimated response functions. After the response functions of each dipole were obtained, the impedance tensors were estimated by using a linear combination of the two response functions.

The study area is characterized by a distinguishing zonal arrangement of geological terranes (Fig. 1), whose general trend is $\mathrm{N} 75^{\circ} \mathrm{E}$. The strike of the Nankai Trough, where the Philippine Sea plate is subducting beneath the region, is uniform. Sets of principal axes were found by the method of Swift (1967). These sets of principal axes for the different sites were found to be closely constant in orientation, and parallel and perpendicular to the general geologic strike. For period $64 \mathrm{sec}$, the 2-D strike axes are plotted in Fig. 2(a), and for period $2560 \mathrm{sec}$, in Fig. 2(b). The plotted axes have more constancy of direction for the longer period $(2560 \mathrm{sec})$.

For an MT impedance tensor, the determination of principal axes, using for example the method of Swift (1967), results in an ambiguity. The ambiguity is that it is not known which of the axes is the TE-mode, and which is the TMmode. In the present case, this ambiguity is solved by knowledge of which axis is across strike, and which axis is along strike. Thus, in discussion of TE and TM-modes below, 


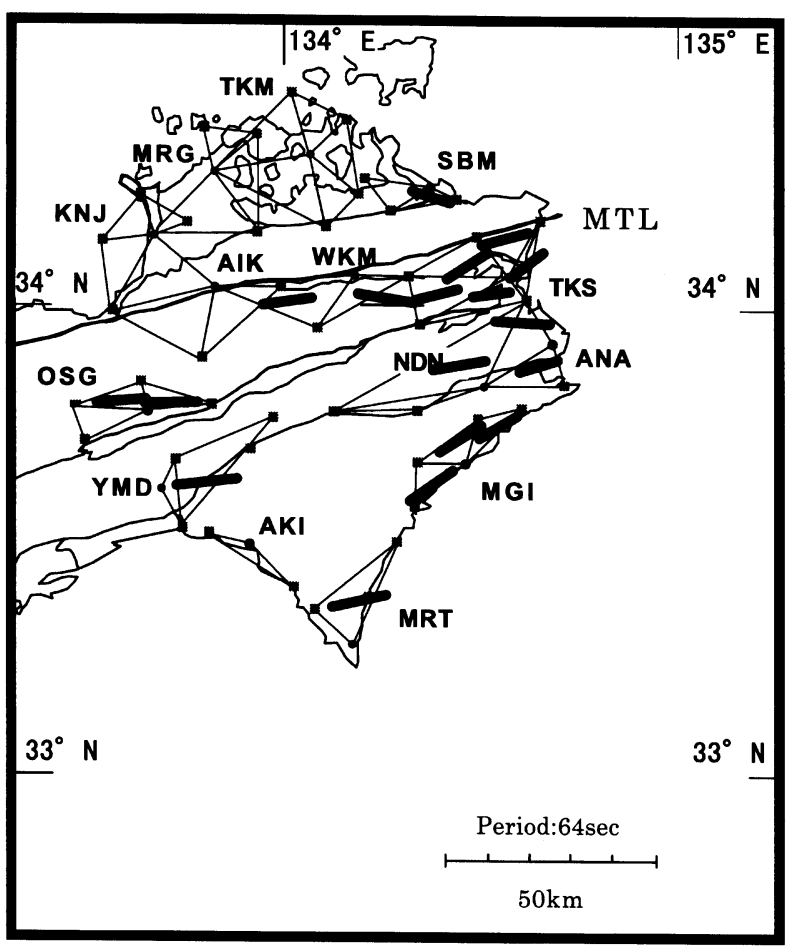

(a)

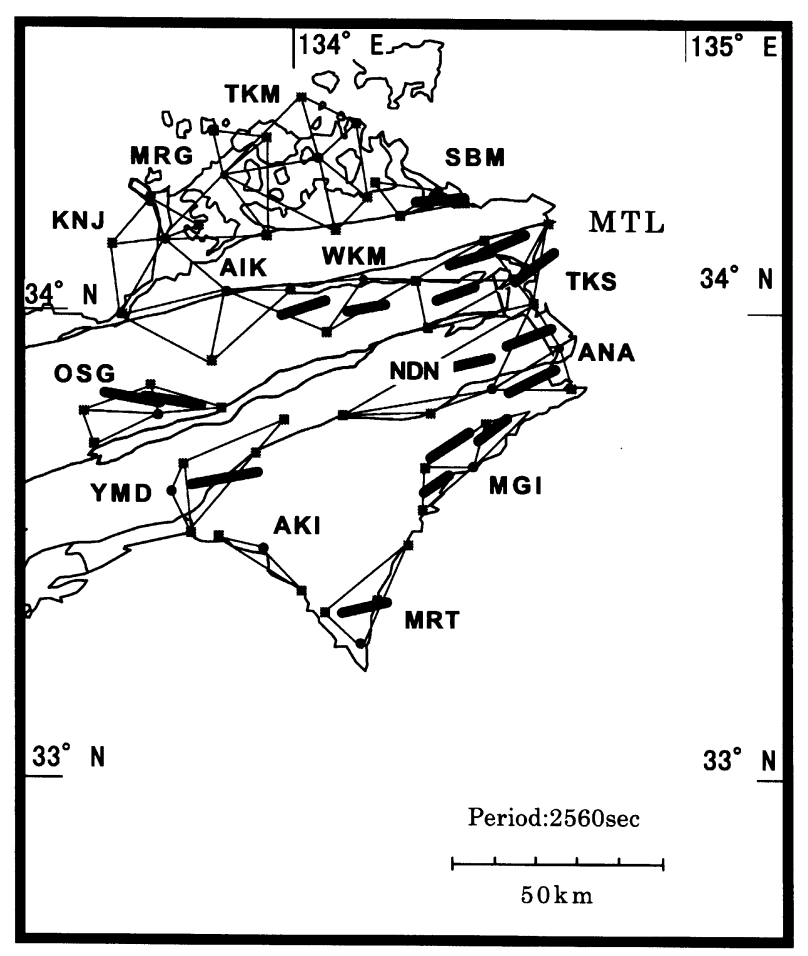

(b)

Fig. 2. The spatial distribution of principal axes (a) at a period of $64 \mathrm{sec}$. (b) at a period of 2560 sec. The closed circles, with abbreviated location names, represent the central stations; the gray squares represent the telephone branch stations.

the TE-mode has the magnetic component across geologic strike $\left(\mathrm{N} 75^{\circ} \mathrm{E}\right)$, and the TM-mode has the electric component across geologic strike.

\section{MT Responses and Their Spatial Distribution}

MT impedances were estimated at all triangular elements which are formed by one central site and two branch sites adjoining each other, but we could not determine stable MT responses at some triangular elements (Fig. 3). These unsatisfactory elements can be divided into three groups: (1) Those whose triangular elements have an electrode on small islands off Shikoku island, (2) Those in the northwestern part of the area (e.g. the AIK, MRG, KNJ, TKM nets), and (3) Those triangular elements with a very acute- (and/or very obtuse-) angle (e.g. the AKI net). For the first group, the amplitude of the noise is larger than the signal, so that correlation between the electric and magnetic field is poor. We think that this effect is caused by the concentration of artificial electric currents in the seawater, from electric railways and factories. For the second group, the amplitude of noise is generally less than for the first group, but sometimes it is larger than the signal in the short period range. This noise is mainly caused by leakage current from electric railways, judging from its characteristic waveform. Regarding the third group, for the Network MT method, one calculates the MT impedance for a triangular element from two response functions, as mentioned above. Therefore, it difficult to determine stable impedance values for a triangle which has a very acute- (and/or obtuse-) angle, because of experimental

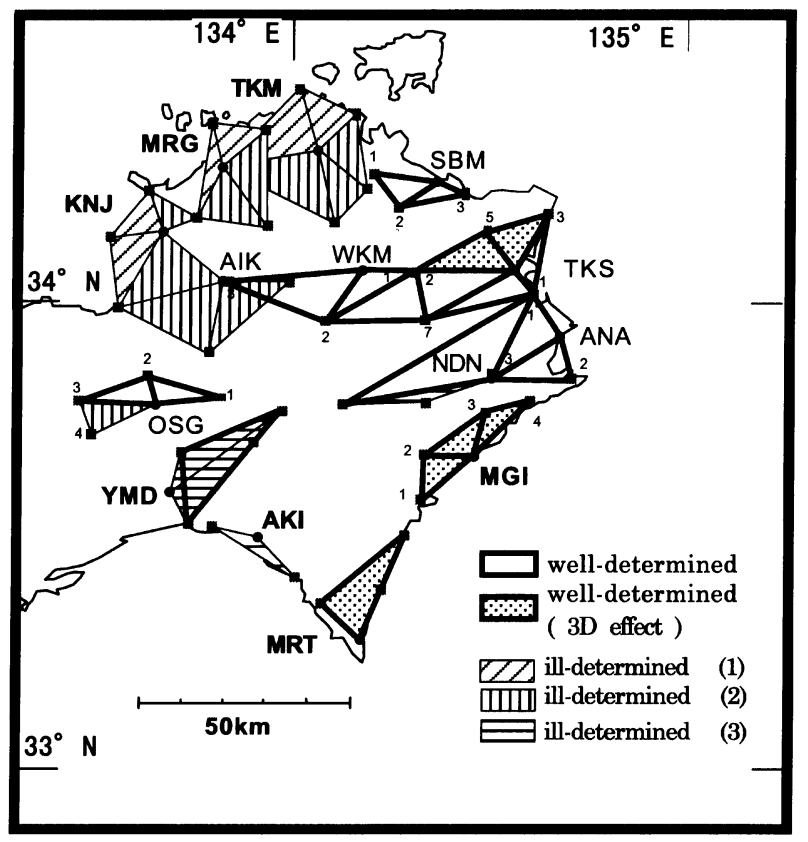

Fig. 3. Quality of MT impedances for selected triangular elements. Stable MT impedances were obtained for open triangular elements. The dotted elements show the triangles which may be affected by three-dimensional effects. The oblique striped triangular elements (1) have one corner on an islet, off Shikoku island. The vertical striped triangular elements (2) show those with large artificial noise in the electric field. The horizontal striped triangular elements (3) have a strong acute- and/or obtuse-angle. 

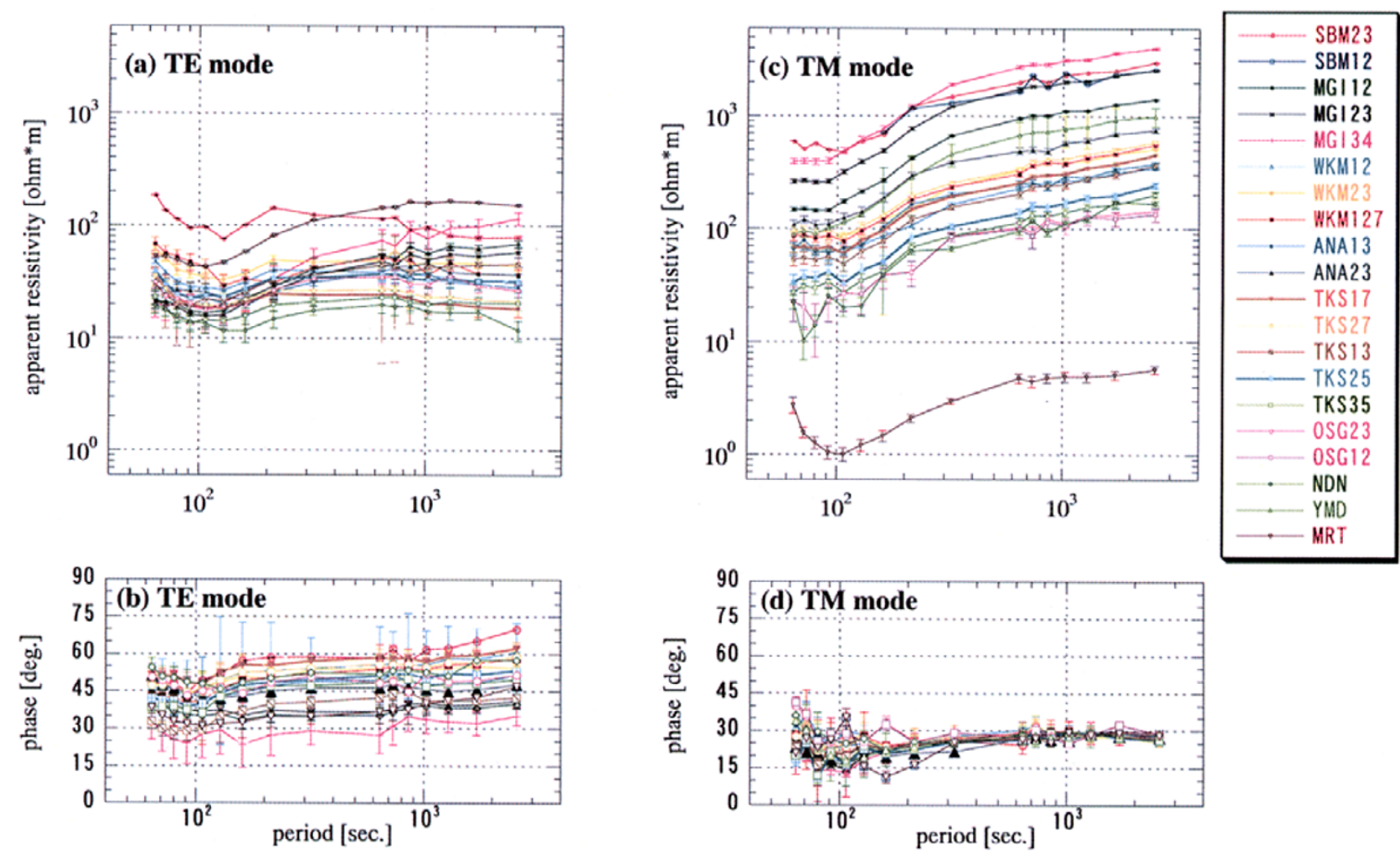

Fig. 4. Sounding curves for each triangular element. (a) Apparent resistivity curves for the TE-mode. (b) TE-mode impedance phase curves. (c) Apparent resistivity curves for the TM-mode. (d) TM-mode impedance phase curves.

geometry. For such cases, we used other combinations that allowed for a more regular triangle. Finally, we neglected triangular elements, which exhibited error larger than $25 \%$ for the MT impedance.

The TM response curves for selected triangular elements are shown in Figs. 4(a)-(d). The TM-mode impedance phases are scattered in the range of $15^{\circ}$ to $40^{\circ}$, for the short period range, but converge to about $30^{\circ}$, as the period increases (Fig. 4(d)). The apparent resistivity of the TM-mode increases, as the period increases; but the rate of increase tends to diminish as the period increases (Fig. 4(c)). The curves are classified into three groups by their values. The first group consists of the SBM and MGI nets, which show large apparent resistivity. The second group consists of the MRT and OSG nets and two triangular elements of the TKS nets (TKS25 and TKS35); this group shows a very small apparent resistivity. The remainder forms the third group.

In contrast to the TM-mode, the apparent resistivities for the TE-mode do not show a steep increase (Fig. 4(a)). Almost all apparent resistivity curves in TE-mode show minimum values at 100-200 sec. Then, the apparent resistivities of the two nets and one triangular element (MGI, MRT nets and TKS13) increase monotonously with the period. Other nets (SBM, WKM, ANA, TKS (except TKS13), and OSG) decrease with the period after showing a local maximum at 200-700 sec. In general, the phase value of the TE-mode consistently varies with the variation of apparent resistivity.

As already noted, all triangular elements for the MGI,
MRT nets, and two elements of the TKS net (TKS25 and TKS35), show particularly large or small apparent resistivity values of the TM-mode. We think that these effects are caused by the three-dimensional nature of the resistivity structure. The MRT net covers an area on a triangular shaped peninsula that extended into the Pacific Ocean. The MGI net is located along the coastline, running from NE to $\mathrm{SW}$. There the coast is not aligned with the general trend in topography and geologic terrane. The two elements of the TKS net, (TKS25 and TKS35) are located on a triangular area, near an estuary. TKS13 is also affected by a 3D effect. It is not clear why the YMD and WKM127 nets show low phase values.

The behavior of the MT response for most of the triangular elements may be summarized as follows. Firstly, the apparent resistivities for the TM-mode are in the range of $10^{2}-10^{3} \Omega \mathrm{m}$, and for that of the TE-mode in the range of $10^{1}-10^{2} \Omega \mathrm{m}$. Secondly, TM-mode impedance phase is scattered in the range of $15^{\circ}-40^{\circ}$ for the short periods but then converges to about $30^{\circ}$ as period increases. The impedance phase of the TE-mode in the short period range is between $25^{\circ}$ and $60^{\circ}$. The apparent resistivity for the TE-mode does not show a steep increase. The six of eight nets decrease with the period at the period longer than 200-700 sec. One triangular element (SBM) shows large apparent resistivity. This element is on a northern side of the Median Tectonic Line. All the other elements show small apparent resistivity, and they are on the southern side of the Median Tectonic Line. 


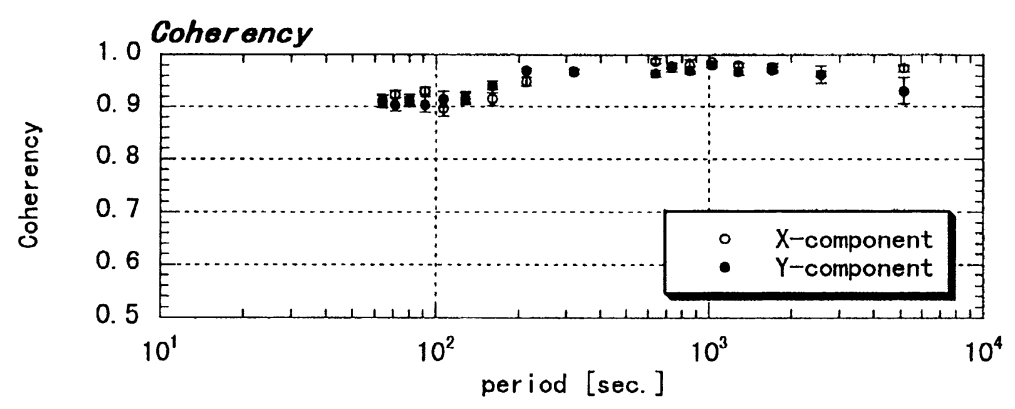

(a)

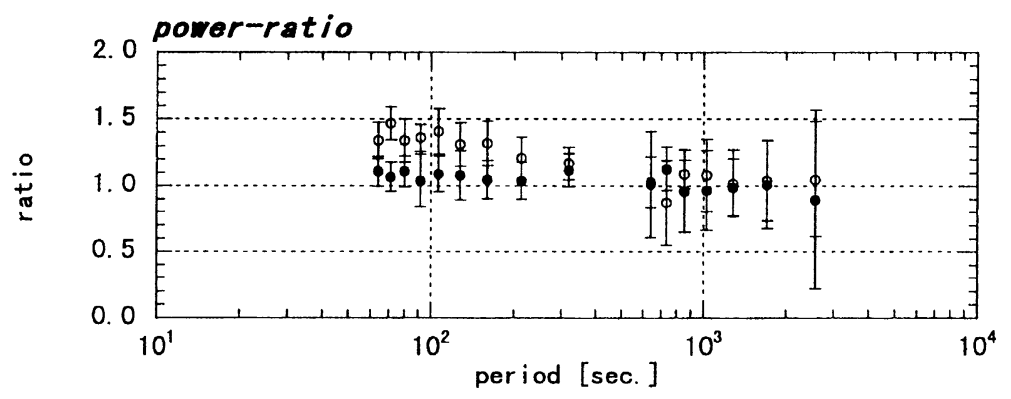

(b)

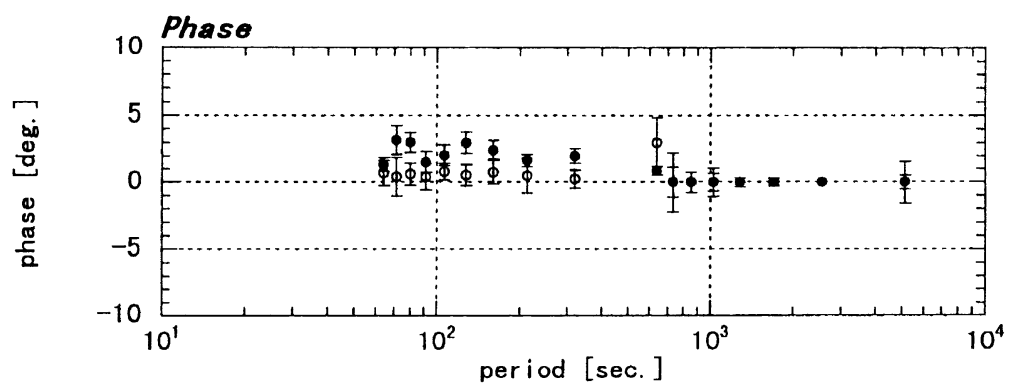

(c)

Fig. 5. Coherency, power-ratio, and phase difference for the two horizontal magnetic components, between the Kakioka Geomagnetic Observatory (KAK) and the temporary magnetic observation station (UMJ). (a) Coherency between UMJ and KAK. The coherency of the northward components ( $X$ ) is shown by open circles. The coherency of the eastward components $(Y)$ is shown by closed circles. (b) Power-ratio at UMJ and KAK, for the $X$ and $Y$ components. (c) Phase difference at UMJ and KAK, for the $X$ and $Y$ components.

\section{Two-Dimensional Resistivity Model}

Preliminary two-dimensional resistivity models were obtained by "trial and error" fitting of the observed data, using the finite element forward programs of Uchida and Ogawa (1993). The cross section was determined along the line crossing the eastern part of the area, see Fig. 1. This line was chosen as it passes through the SBM triangular element, the only well-determined triangular element on the north side of the Median Tectonic Line; also this part of the area studied is best covered by our observation nets, with no large gap in the observation data. The resistivity values for the section were derived from the TM-mode data, since the two-dimensional assumption for this mode is usually more robust than the TE-mode (Wannamaker et al., 1989).

Use of the Kakioka data for computing an MT impedance is justified by a quantitative study of coherency, power ratio, and phase differences between the KAK station and the local magnetic station (UMJ), which operated temporarily in the study area from November to December 1994. Figure 5(a) shows the coherency of the $X$ and $Y$ components of the geomagnetic fields for and the Kakioka Observatory (KAK).
The coherency of both components is greater than 0.9 over the whole range of periods. Furthermore, it is greater than 0.95 at a period greater than $200 \mathrm{sec}$. The high coherency of both components over the whole range of periods gives confidence that it is valid to use the magnetic field components at the Kakioka observatory when calculating the MT responses in the study area. We examined the power ratio and phase difference of each component between the two sites (Fig. 5(b)). The power of the $X$ component at UMJ is larger than that at KAK. The ratio $\left(X_{\mathrm{UMJ}} / X_{\mathrm{KAK}}\right)$ shows that the maximum value of 1.5 , at the shortest period, decreases gradually to unity as the period increases. The ratio of the $Y$ components lies between 1.2 to 0.9 for all of the period range. The phase differences of the $Y$ components are less than 3 degrees for the period less than $731 \mathrm{sec}$, and the phase differences of the $X$ component are less than 1 degree for all periods except at $731 \mathrm{sec}$ (Fig. 5(c)). The phase differences for both components tend to be zero for periods longer than about $700 \mathrm{sec}$.

For the study area, the TM-mode involves a horizontal geomagnetic component of $H_{y} \cos \left(15^{\circ}\right)+H_{x} \sin \left(15^{\circ}\right)$. The 


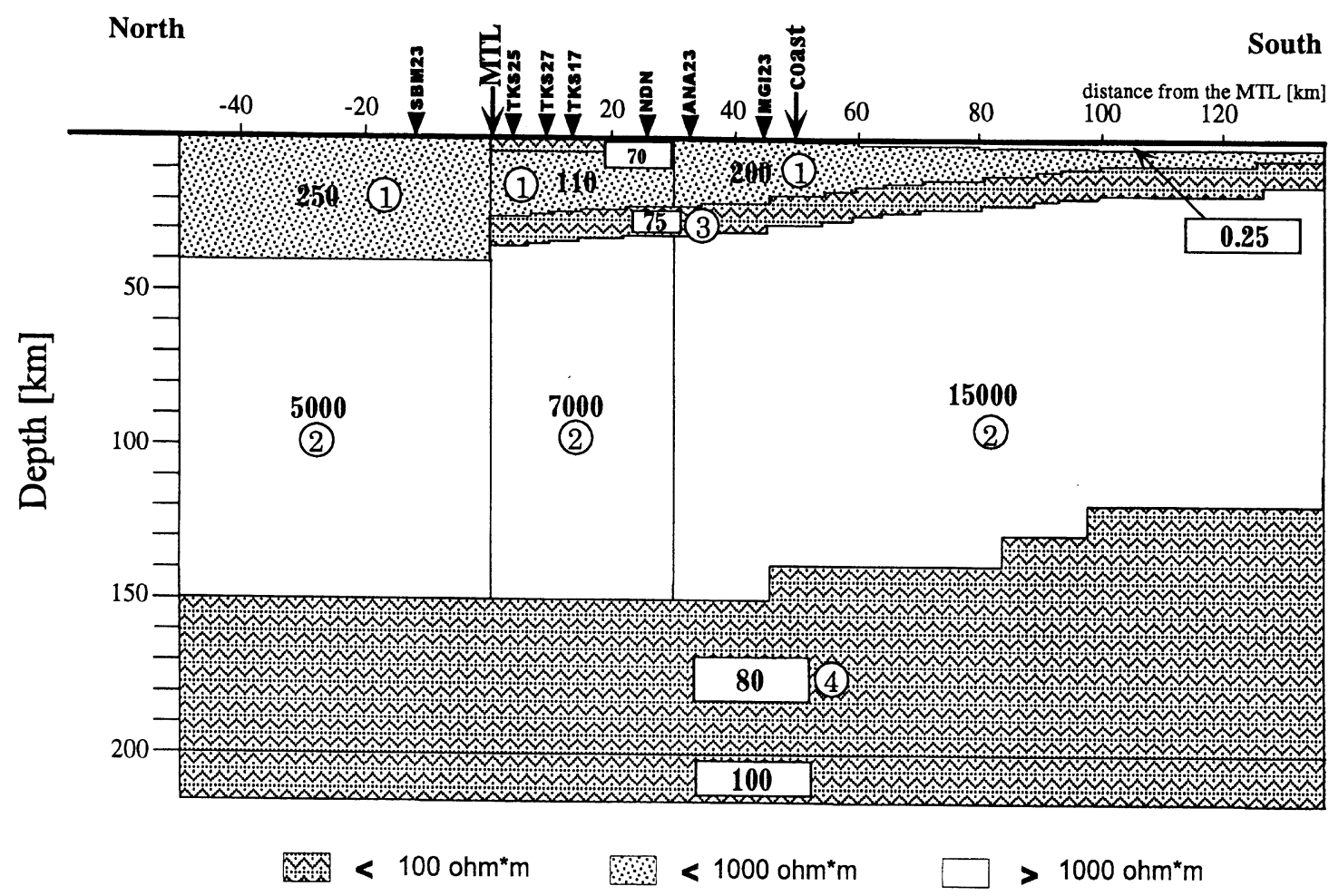

Fig. 6. The two-dimensional resistivity cross section derived from forward modeling of the Network-MT data beneath the eastern part of the Shikoku district. The resistivity for each block is written in $\Omega \mathrm{m}$. Hatching emphasizes the major structure.

percentage of the $Y$ component in the horizontal component is large (about 80\%). Furthermore, as the magnetic field can be regarded as the same value over the profile in the TMmode, it is reasonable to use the magnetic field components at one site (KAK) for calculating the responses at all triangular elements in the study area. Thus, we decided that the magnetic field components at the Kakioka observatory are available as the input magnetic field component for all triangular elements.

In the Network-MT method, the mean electric field in a triangular element is obtained from a linear combination of two electric fields along two sides of a triangle. These electric fields are computed by dividing the electrode separation into the electric potential difference. Poll et al. (1989) pointed out that this procedure of computing the electric field gives the true value of the electric field only if it is uniform between the electrodes.

Therefore, we estimated the effect of non-uniformity of the electric field between two electrodes. First, the potential difference between two electrodes was obtained by integrating electric field values along the dipole, which were calculated from the final model, being described below (Fig. 6). Then, we computed the mean impedance of a triangular element from the mean electric field computed by dividing the electrode separation into the electric potential difference. Next, we compared the mean impedance and the impedance calculated at the center of triangular elements.

The latter impedances of triangular elements, except the ANA23 element, showed a little deviation from the impedance at the center (less than 15\%). We can say that the deviation is small enough. As the ANA23 element has a large deviation of $45 \%$, we did not stress the apparent resistivity at the ANA23 element when deciding the 'best' model. Furthermore, the 'best' model explained the phase value at all triangular elements. We confirmed that the phase values did not show a gap at the resistivity boundaries. Therefore, it is reasonable to decide the 'best' model based on the impedances calculated at the center of each triangular element instead of the impedances calculated by considering the finite length of each dipole.

However, of course, it is desirable to modify the computing method of the electric field in order to make the NetworkMT method more robust for any kind of resistivity structure and an electrode configuration. In the TM-mode, it is better that voltage divided by electrode separation be used as the 'electric field' in model calculations to compare model with experiment on an equal basis, as pointed out by Poll et al. (1989). On the other hand, in the TE-mode, it is necessary to numerically compute the potential difference between two electrodes from values of an electric field along a dipole.

Several constraints were imposed on the model geometry. Firstly, seafloor topography was carefully read along the profile from the bathymetric chart, and secondly the shape and depth of the upper plane of the Philippine Sea plate, downgoing to north, was determined by referring to the distribution of microearthquake foci (Kimura and Okano, 1992). The bottom plane of the downgoing plate was set parallel to the upper plane. Finally, a thin block was placed on the upper plane of the Philippine Sea plate. This block was installed to confirm the existence of the high conducting layer on which 

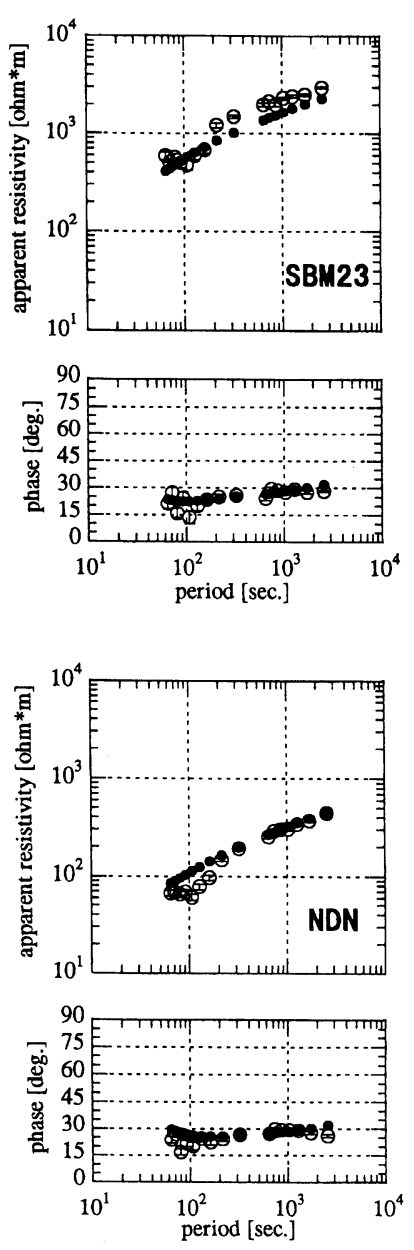
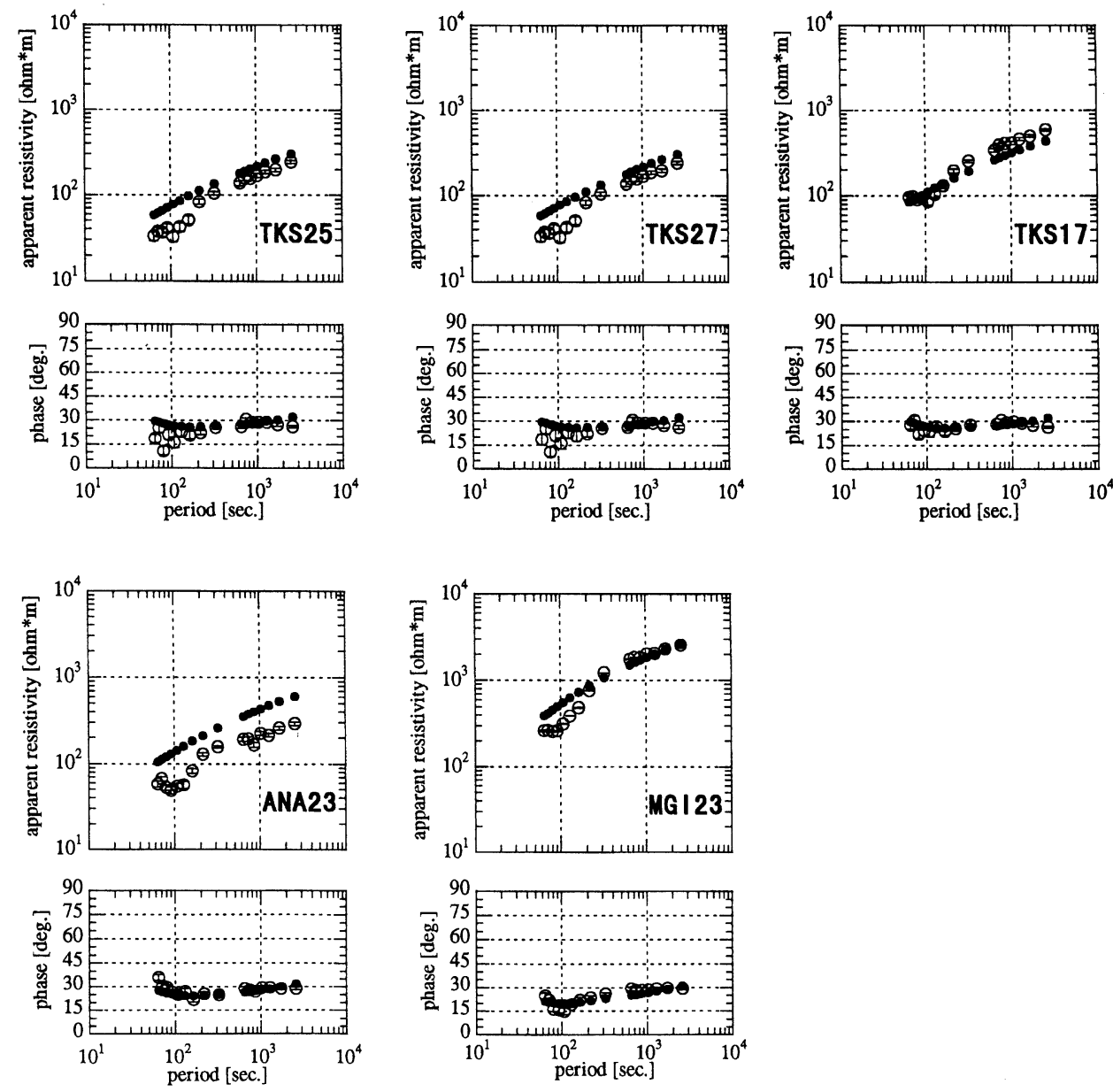

Fig. 7. Comparison of calculated apparent resistivity and phase values for each triangular element with observed values. The open circles show observed values with error. The closed circles show calculated values.

many researchers were reported (e.g. Wannamaker et al., 1989; Utada et al., 1996).

Figure 6 shows a model, thus determined, that gives a reasonable fit to the observations. The calculated responses, at the center of triangular elements, for the TM-mode of this model are shown in Fig. 7, together with the observed data. Four features are evident. First, the shallower part (1) in model, Fig. 6), less than $40 \mathrm{~km}$ deep on the north side of the Median Tectonic Line and $20 \mathrm{~km}$ deep at the coast, is generally moderately conductive. It has a resistivity of $110-250 \Omega \mathrm{m}$ (except the near-surface layer immediately to the south of the Median Tectonic Line). More resistivity boundaries, which do not coincide with the tectonic line, are not required.

Second, the downgoing plate is presented as a group of highly resistive blocks of 5,000 $\Omega \mathrm{m}, 7,000 \Omega \mathrm{m}$, and 15,000 $\Omega \mathrm{m}$ (2) in model). The resistivity decreases with distance inland. The thickness of all of these blocks is $100 \mathrm{~km}$ for this combination of block resistivities. Third, a highly conductive layer (3) in model), on a highly resistive downgoing plate (2) in model), is required for the model. The thickness and resistivity values of the layer are $10 \mathrm{~km}$ and $75 \Omega \mathrm{m}$, respectively. It should be noted that the conductive thin layer is only found to the south side of the Median Tectonic Line.
Fourth, a conductive layer (4) in model), of less than $100 \Omega \mathrm{m}$, exists below the highly resistive blocks.

\section{Discussion}

The layer (1) in the model, Fig. 6) above the fixed upper plane of the subducting plate may be divided into three blocks. The northernmost block, situated on the north side of the Median Tectonic Line, has the largest resistivity of the three blocks. The resistivity of this block is $250 \Omega \mathrm{m}$ and is twice as large as the resistivity of the block located immediately to the south of the Median Tectonic Line; the latter block is beneath the Sambagawa metamorphic belt and the north part of the Chichibu belt. The southernmost part of the shallow layer is $200 \Omega \mathrm{m}$, which is in the middle of the range of the resistivities proposed for the two blocks located in the north.

Granitic rock is abundantly exposed on the north side of the Median Tectonic Line (the Inner Zone), while the south side of the Median Tectonic Line (the Outer zone) is known to have grown by accretion processes in the Jurassic to the Lower Miocene from north to south (Taira et al., 1989). The resistivity of granite at the Earth's surface is commonly greater than 3,000 $\Omega \mathrm{m}$ (Jones, 1992), while the resistivity of old sediments (such as the accretionary prism) may be hun- 
dreds of ohm-meters (Jones, 1992). The difference in the apparent resistivity in the short period range observed between both sides of the Median Tectonic Line is interpreted as being due to the difference in rock types.

To fit the short period data, a highly conductive layer $(4 \mathrm{~km}$ and $70 \Omega \mathrm{m}$ ) needs to be incorporated at the shallowest part to the immediate south of the Median Tectonic Line. The existence of this layer was suggested by Goto et al. (1998) from AMT and ELF-MT observations. However, the low resistivity observed for the block south of the Median Tectonic Line cannot be explained with only a near-surface layer. This result suggests that a high conductive block exists in the crust. Such a structure would be consistent with the previous study of Shiozaki (1993), who proposed the existence of a highly conductive block beneath the Sambagawa belt and the northern part of the Chichibu belt. Fuji-ta et al. (1997) also found the high conductive layer in the crust beneath the Kii peninsula, which is located to the east of the Shikoku island, using the MT method.

There is a thick $(=100 \mathrm{~km})$ layer with a high resistivity below the fixed upper plane of the Philippine Sea plate which becomes conductive as it approaches the north coast of the Shikoku district $(15,000 \Omega \mathrm{m} \rightarrow 7,500 \Omega \mathrm{m} \rightarrow 5,000 \Omega \mathrm{m})$. Utada et al. (1996) estimated the thickness and the resistivity of the lithosphere using the results of soundings at two seafloor magnetotelluric sites. They suggested values of 30 $\mathrm{km}$ and $500 \Omega \mathrm{m}$ in the northeastern part of the Philippine Sea. Our estimates for the resistivity and thickness of the plate are larger than the results of Utada et al. (1996). If the plate thickness is reduced to $30 \mathrm{~km}$, then for the same conductance (thickness/resistivity), the resistivity of the layer needs to be 4,500-1,500 $\Omega \mathrm{m}$, which is larger than the value of $500 \Omega \mathrm{m}$ estimated by Utada et al. (1996). However, the plate resistivity is close to the estimate of $3,000 \Omega \mathrm{m}$ for the Juan de Fuca plate by Wannamaker et al. (1989), or the 5,000 $\Omega \mathrm{m}$ estimated by Kurtz et al. (1986). Our estimate lies between these two and the conductance of the plate is plausible; however, further analysis is required to determine the thickness and resistivity of this layer.

A thin conductor was detected at the top surface of the subducting plate. This feature was tested by replacing the highly conductive layer with a moderately resistive layer $(110 \Omega \mathrm{m}$ to the middle block and $200 \Omega \mathrm{m}$ to the southern block). This test showed the TM-mode responses at all sites are sensitive to the thin highly conductive layer, and the test calculation gave worse fit. Therefore, we conclude that the model requires a thin conductive layer on the resistor (subducting plate).

We tested again how far this conductive thin layer extends inland by comparing several models. It became clear that the calculated MT response for the model that allowed the thin conductive layer to extend northward beyond the Median Tectonic Line differed greatly from the observed values. Therefore, we concluded that the thin conductor on the subducting plate is restricted to the south side of the Median Tectonic Line.

The resistivity of the thin conductive layer is $75 \Omega \mathrm{m}$ and its thickness is $10 \mathrm{~km}$, so its conductance is about $130 \mathrm{~S}$. This result is comparative to the results of Kurtz et al. (1986) for Vancouver Island, Wannamaker et al. (1989) for the Coast
Range and westernmost William Basin, and Utada et al. (1996) for northeastern Japan and central Japan.

The thermal structure beneath the Japan arc has been estimated from surface heat flow data (Furukawa, 1995). The temperature at a depth of $30 \mathrm{~km}$ is about $600^{\circ} \mathrm{C}$ at the southern coast, and $400^{\circ} \mathrm{C}$ at the northern coast of the Shikoku district. Such temperature estimates correlate with the depth $(25 \mathrm{~km})$ to the thin conductor in Fig. 6 beneath the southern coast, and $35 \mathrm{~km}$ beneath the Median Tectonic Line. Thus, the temperature of the thin conductor is estimated to be in the range of $400-600^{\circ} \mathrm{C}$, which is too low to induce partial melting of basalt (Shankland and Waff, 1977).

It has been reported that deep sediments have been carried beneath the leading edge of the overriding plate at the Nankai trough (Hilde, 1983). We think that pore water and/or sediment along the upper plane of the subducting Philippine Sea plate explains the high conductivity of this thin plate. A simple form of Archie's law, with an exponent of two, is widely used to study sedimentary rock. According to this relation, the porosity estimated for the thin conductive layer is between $1-2 \%$, supposing the resistivity of the layer is 50 $110 \Omega \mathrm{m}(75 \Omega \mathrm{m} \pm 50 \%)$. We think that this value may be realistic, but acknowledge that a more precise calculation is required to determine the resistivity, thickness, and position. The question regarding position is whether the thin layer exists precisely at the plate interface, or above the plate surface (shown by Hyndman, 1988).

In the model of Fig. 6, another low resistive layer (80$100 \Omega \mathrm{m}$ ) exists beneath the highly resistive Philippine Sea plate. This feature was tested by replacing the conductive layer $(80 \Omega \mathrm{m})$ with the resistor $(5000,7000$, and $15000 \Omega \mathrm{m})$, in other words, making all of the bottom depth of the resistor $200 \mathrm{~km}$. This test showed no difference in the model responses of the inland sites (SBM23, TKS25, and TKS27). However, at the coastal site (TKS17, NDN, ANA23, MGI23), the TM-mode is sensitive to the deep structure and the test calculation gave a worse fit at the periods longer than $200 \mathrm{sec}$. Thus, the model requires a deep conductor at $120-150 \mathrm{~km}$, at least beneath the resistor near the coast, but its northern extension is not guaranteed.

The existence of a highly conductive layer with a resistivity of about $10 \Omega \mathrm{m}$ is a common feature of the upper mantle beneath a major ocean (e.g. Filloux, 1980, 1981). The high conductivity is due to partial melting of the upper mantle (Oldenburg, 1981) or to solid-state conductivity in the olivine with a small amount of hydrogen (Karato, 1990).

\section{Conclusions}

Observations for the Network MT method were carried out in the eastern part of the Shikoku district, southwestern Japan, and a total of thirty-nine MT impedances were obtained. These MT impedances are values averaged over triangular elements whose sides are as long as a few kilometers. The well-determined MT impedances vary from north to south, and change greatly at the Median Tectonic Line; this feature is consistent with the geology. Very large or very small values for apparent resistivity were obtained for some triangular elements; generally, these are located on triangular capes or triangular sediment patches near estuaries, and the results are attributed to three-dimensional effects. 
Stable MT impedances were not obtained for some triangular elements. In summary, the triangular elements may be divided into three groups: (1) Those whose triangular elements have an electrode on an islet off Shikoku island. (2) Those in the northwestern part of the area (e.g. the AIK, MRG, KNJ, TKM nets), and (3) Those triangular elements whose triangle has very acute- and/or very obtuse-angle (e.g. the AKI net).

Preliminary two-dimensional resistivity models for the eastern part of the Shikoku district were derived by trial and error fitting of the observed data. A 'best' model was derived by emphasizing the TM-mode data, since the assumption of two-dimensionality is more relevant for this case. The features of the model are as follows;

(1) The shallower layer, which generally corresponds to the crust, may be divided into three blocks. Two resistive boundaries coincide with the geological tectonic lines; and the strongest horizontal contrast is found at the Median Tectonic Line. The northernmost block, which is on the north side of the Median Tectonic Line, is the most resistive block; while the block to the south of the Median Tectonic Line is the most conductive.

(2) The subducting Philippine Sea plate may be represented by a thick $(=100 \mathrm{~km})$ and highly resistive $(15000$ $5000 \Omega \mathrm{m}$ ) layer whose resistivity decreases toward the land. The estimated conductance of this layer is thought to be correct, however further data and analysis is necessary to decide the thickness and resistivity values separately.

(3) On the top of the subducting Philippine Sea plate, there is a highly conductive thin layer ( $75 \Omega \mathrm{m}$ and $10 \mathrm{~km}$ ). It is worthwhile to note that this layer is only found beneath the southern side of the Median Tectonic Line. The highly conductive layer is probably caused by pore water and/or sediment at the upper plane of the subducting Philippine Sea plate.

(4) Another conductive layer, of less than $100 \Omega \mathrm{m}$, exists beneath the highly resistive Philippine Sea plate. This layer is consistent with a general feature of major oceans.

In order to clarify the spatial distribution of MT impedances, obtained by the Network MT method, of the whole of the study area, further developments are needed in methods of data analysis. This need arises particularly where the electric field data are severely contaminated by artificial electric noise, mainly due to leaking of current from electric railways. In addition, the area bounded by the NYD, YMD, and MRT nets needs to be surveyed by a new type of net, which is composed of branch telephone stations and some electrodes at individual houses linked to the telephone stations by metallic lines.

Acknowledgments. We are deeply indebted to the staff of Nippon Telegraph and Telephone Corporation (NTT) for their assistance in setting up and maintaining the stations, in the Shikoku district. We thank Alan Jones and two anonymous referees for their constructive comments which have improved the paper considerably. Our special thanks are due to Dr. F. E. M. (Ted) Lilley for reading the manuscript and making a number of helpful suggestions. We would like to thank Dr. Terry Lee, who improved the presentation and language of the full text by careful and critical editing. Part of the research was financially supported by the Ministry of Education, Culture and Science, Japan, through Grant-in-Aid for Co-operative Research (A), No. 05302022.

\section{References}

Bendat, J. S. and A. G. Piersol, Random Data: Analysis and Measurement Procedures, 407 pp., John Wiley and Sons, Inc., New York, 1971.

Filloux, J. H., Magnetotelluric sounding over the north-east Pacific may reveal spatial dependence and conductance of the asthenosphere, Earth Planet. Sci. Lett., 46, 244-252, 1980.

Filloux, J. H., Magnetotelluric exploration of the North Pacific: progress report and preliminary soundings near a spreading ridge, Phys. Earth Plant. Inter., 25, 187-195, 1981

Fuji-ta, K., Y. Ogawa, S. Yamaguchi, and K. Yaskawa, Magnetotelluric imaging of the SW Japan forearc-a lost paleoland revealed?, Phys. Earth Planet. Inter., 102, 231-238, 1997.

Furukawa, Y., Temperature structure in the crust of the Japan arc and the thermal effect of subduction, in Terrestrial Heat Flow and Geothermal Energy in Asia, edited by M. L. Gupta and M. Yamano, pp. 203-219, Oxford \& IBH Publishing Co. Pvt. Ltd., New Delhi, 1995.

Goto, T., S. Yamaguchi, N. Sumitomo, and K. Yaskawa, The electrical structure across the Median Tectonic Line in east Shikoku, southwest Japan, Earth Planet. Sci., 50, 405-415, 1998.

Hada, S., T. Suzuki, K. Okano, and S. Kimura, Crustal section based on the geological and geophysical features in the Outer Zone of southwest Japan, Mem. Geol. Soc. Japan, 21, 197-211, 1982.

Hilde, T. W. C., Sediment subduction versus accretion around the Pacific, Tectonophysics, 99, 381-397, 1983.

Hyndman, R. D., Dipping seismic reflectors, electrically conductive zones, and trapping water in the crust over a subducting plate, J. Geophys. Res. 93, 13391-13405, 1988 .

Jones, A. G., Electrical conductivity of the continental lower crust, in Continental Lower Crust, edited by D. M. Fountain, R. Arculus, and R. W. Kay, pp. 81-143, Elsevier, Amsterdam, 1992.

Karato, S., The role of hydrogen in the electrical conductivity of the upper mantle, Nature, 347, 272-273, 1990.

Kimura, S. and K. Okano, A seismological examination of the Median Tectonic Line and its surrounding area in Shikoku, Southwest Japan, Mem. Geol. Soc. Japan, 40, 187-195, 1992.

Kurtz, R. D., J. M. DeLaurie, and J. C. Gupta, A magnetotelluric sounding across Vancouver Island detects the subducting Juan de Fuca plate, Nature, 321, 596-599, 1986.

Ogawa, Y., Two-dimensional resistivity modeling based on regional magnetotelluric survey in the northern Tohoku district, J. Geomag. Geoelectr. 39, 349-366, 1987.

Ogawa, Y., T. Yukutake, and H. Utada, Two-dimensional modeling of resistivity structure beneath the Tohoku district, northern Honshu of Japan, by a finite element method, J. Geomag. Geoelectr., 38, 45-79, 1986.

Oldenburg, D. W., Conductivity structure of oceanic upper mantle beneath the Pacific plate, Geophys. J. R. astr. Soc., 65, 359-394, 1981.

Poll, H. E., J. T. Weaver, and A. G. Jones, Calculations of voltages for magnetotelluric modeling of a region with near-surface inhomogeneities, Phys. Earth Planet. Inter., 53, 287-297, 1989.

Saito, M., Automatic design of recursive digital filters, Geoexploration, $\mathbf{3 1}$ 240-263, 1978.

Shankland, T. J. and H. S. Waff, Partial melting and electrical conductivity anomalies in the Upper Mantle, J. Geophys. Res., 82, 5409-5417, 1977.

Shiozaki, I., Two-dimensional resistivity structure beneath Chugoku and Shikoku districts in Southwestern Honshu, Japan, Ph.D. Thesis, Kobe University, 276 pp., 1993 (in Japanese).

Sugimura, A., Chikyu-Kagaku, vol. 10, edited by K. Kasahara and A. Sugimura, pp. 159-181, Iwanami-syoten, Tokyo, 1978.

Suyari, K., M. Iwasaki, and T. Suzuki, Regional Geology of Japan, Part 8, SHIKOKU, edited by Editorial Committee of SHIKOKU, Part 8 of Regional Geology of Japan, Kyoritsu Shuppan, Tokyo, 1991.

Swift, C. M., Jr., A magnetotelluric investigation of an electrical conductivity anomaly in the southwestern United State, in Magnetotelluric Methods, Geophys. Reprint Series, vol. 5, edited by K. Vozoff, pp. 156-166, Soc. Explor. Geophys., Tusla, Okla., 1986 (extract from a thesis submitted to Dep. Geol. Geophys., M. I. T., 1967).

Taira, A., H. Tokuyama, and W. Soh, Accretion tectonic and evolution of Japan, in The Evolution of the Pacific Ocean Margins, edited by Z. Ben- 
Avraham, pp. 100-123, Oxford Univ. Press, New York, 1989.

Uchida, T. and Y. Ogawa, Development of Fortran code for two-dimensional magnetotelluric inversion with smoothness constraint, Geological Survey of Japan Open-File Report, No. 205, 115 pp., 1993.

Utada, H., Y. Hamano, and J. Segawa, Conductivity anomaly around the Japanese Islands, in Geology and Geophysics of the Japan Sea (JapanUSSR Monograph Series, Vol. 1), edited by N. Isezaki, I. I. Bersenev, K. Tamaki, B. Ya. Karp, and E. P. Lelikov, pp. 103-149, Terra Sci. Pub., Tokyo, 1996.

Uyeshima, M., Application of Network MT method to the study of electrical conductivity structure in the central and eastern part of Hokkaido, Dr. Sc.
Thesis, Univ. Tokyo, 235 pp., 1990.

Wannamaker, P. E., J. R. Booker, A. G. Jones, A. D. Chave, J. H. Filloux, H. S. Waff, and L. K. Law, Resistivity cross section through the Juan de Fuca subduction system and its tectonic implications, J. Geophys. Res., 94, 14127-14144, 1989.

S. Yamaguchi (e-mail: yanchi@kobe-u.ac.jp), Y. Kobayashi, N Oshiman, K. Tanimoto, H. Murakami, I. Shiozaki, M. Uyeshima, H. Utada, and N. Sumitomo 